\title{
ANALISIS TOTAL PRODUKTIVE MAINTENANCE (TPM) PADA STASIUN KERNEL DENGAN MENGGUNAKAN METODE OVERALL EQUIPMENT EFFECTIVENESS (OEE) DI PT. SURYA AGROLIKA REKSA
}

\author{
Dewi Diniaty $^{1}$, Romli Susanto ${ }^{2}$ \\ Jurusan Teknik Industri \\ Email: dewidiniaty@uin-suska.ac.id,romlisusanto13@gmail.com
}

Fakultas Sains dan Teknologi, UIN Sultan Syarif Kasim Riau

Jl. HR. Soebrantas No. 155 SimpangBaru, Panam, Pekanbaru, 28293

\begin{abstract}
ABSTRAK
PT. Surya Agrolika Reksa adalah salah satu perusahaan yang bergerak dibidang pengolahan kelapa sawit yang terdiri dari beberapa stasiun kerja yaitu Stasiun Loading Ramp, Sterilizer, Tippler, Thressing, Screw Press, Kernel plant, Klasifikasi, Power dan Water Treatment. Stasiun yang sering mengalami kerusakan adalah Stasiun Kernel. Stasiun Kernel terdiri dari beberapa mesin. Mesin yang sering mengalami kerusakan pada Stasiun Kernel adalah mesin Ripple Mill yang berfungsi sebagai mesin pemisah biji $(n u t)$.Tingginya waktu delay dan Downtime yang terjadi selama proses produksi berlangsung menyebabkan kerugian bagi perusahaan. Hal ini dikarenakan kurangnya perawatan pada mesin produksi Kernel tersebut. Tujuan dilakukannya penelitian ini adalah untuk mengetahui efektivitas mesin dengan menggunakan metode Overall Equipment Effectiveness (OEE). Berdasarkan hasil pengolahan data yang dilakukan maka diperoleh nilai OEE pada mesin Ripple Mill sebesar 77,028\% yang didapatkan dari nilai Availibiity sebesar 78,804\%, Performance sebesar 97,809\%, dan Quality sebesar 100\%. Dari hasil tersebut dapat disimpulkan bahwa, mesin Rippel Mill memerlukan perbaikan terutama pada factor Availibility yang menjadi prioritas perbaikan nilai OEE.
\end{abstract}

Kata kunci: Perawatan, Availibiity, Performance, OEE

\begin{abstract}
PT. Surya Agrolika Reksa is one of the companies that in the processing of palm oil consisting of several work stations namely Loading Ramp Station, Sterilizer, Tippler, Thressing, Screw Press, Kernel Plant, Classification, Power and Water Treatment. A station that often suffers damage is the Kernel Station. Kernel station consists of several machines. Machines that often suffered damage to the Kernel Station is a Ripple Mill machine that serves as a nut machine (nut). The high time delay and Downtime that occur during the production process take place causing losses for the company. This is due to lack of maintenance on the Kernel production machine. The purpose of this research is to determine the effectiveness of the machine by using the method of Overall Equipment Effectiveness (OEE). Based on the results of data processing done then obtained the value of OEE on Ripple Mill machine of 77.028\% obtained from the value of Availibiity of $78.804 \%$, Performance of $97.809 \%$, and Quality of 100\%. From these results it can be concluded that, Rippel Mill machine requires improvement, especially on the availability of factors that become priority improvement OEE value.
\end{abstract}

Key word: Maintenance, availibiity, performance, quality, OEE.

\section{Pendahuluan}

Terhentinya suatu proses pada lantai produksi sering kali disebabkan adanya masalah dalam mesin atau peralatan produksi, misalnya mesin berhenti secara tiba-tiba, menurunnya kecepatan produksi mesin, lamanya waktu setup dan adjusment, mesin menghasilkan produk yang cacat dan mesin beroperasi tetapi tidak menghasilkan produk. Hal ini akan menimbulkan kerugian pada perusahaan karena selain dapat menurunkan tingkat efisiensi dan efektifitas mesin 
atau peralatan mengakibatkan adanya biaya yang harus dikeluarkan akibat kerusakan tersebut.

Perusahaan memerlukan suatu perencanaan kegiatan perawatan bagi masing masing mesin produksi untuk memaksimalkan sumberdaya yang ada karena mesin terdiri dari berbagai komponen vital yang mendukung kelancaran operasi, sehingga apabila komponen tersebut mengalami kerusakan maka akan mendatangkan kerugian yang sangat besar bagi perusahaan. Sebelum membuat perencanaan kegiatan perawatan mesin, diperlukan alat yang dapat mengukur kinerja mesin sesuai dengan standar internasional.

PT. Surya Agrolika Reksa adalah salah satu perusahaan yang bergerak dibidang pengolahan kelap sawit yang terdiri dari beberapa stasiun kerja yaitu StasiunLoading Ramp, Sterilizer, Tippler, Thressing, Screw Press, Kernel plant, Klasifikasi, Power dan Water Treatment. Stasiun yang sering mengalami kerusakan dan dilakukan perbaikan adalah Stasiun Kernel.Stasiun Kernel terdiri dari beberapa mesin. Mesin yang sering mengalami kerusakan dan dilakukan perbaikanpadaStasiun Kernel adalahmesinRipple Mill yang berfungsi sebagai mesin pemisah biji (nut). Pada Stasiun Kernel dilakukan proses pemisahan serabut dari biji pada ampas hasil pengempasan yang bertujuan terutama untuk memperoleh biji sebersih mungkin yang kemudian akan menghasilkan inti sawit secara rasional, yaitu kerugian yang sekecil - kecilnya

Penerapan dari program Total Productive Maintanance (TPM) dalam menganalisa keefektifitasan mesin agar dapat mengurangi delay timed engan menggunakan metode Overall Equi pment Effectiveness (OEE) yang digunakan sebagai alat untuk mengukur kinerja dari system produktif (Ansori, 2013). Untuk menganalisis dan menemukan faktor-faktor yang berpengaruh secara signifikan disamping itu untuk mencari penyebabpenyebab yang sesungguhnya terjadi dari suatu masalah digunakan Diagram Ishikawa atau Fishbone (diagram sebab-akibat) (Wignjosoebroto, 2003).

\section{MetodePenelitian}

Pada penelitian ini dilakukan analisis dalam penerapan TPM di PT. Surya AgrolikaReksa, mengetahui nilai Overall Equipment Effectiveness (OEE) dan mengidentifikasikan faktor yang memberikan kontribusi paling besar dengan menggunakan diagram fishbone (diagram sebabakibat).
Loading Time
Loading Time $=$ Available Time-Planned Downtime(2)

\section{HasildanPembahasan}

Untuk menghitung nilai OEE harus menghitung nilai availability ratio, performance effeciency ratio, dan total yield (quality rate), yaitu (MikoHasriyono, 2009):

Berikut adalah data jam kerja Karyawan PT. Surya Agrolika Reksa pada tahun 2016:

Tabel 1 Data Jam Kerja PT. SAR

\begin{tabular}{|l|c|c|c|c|c|c|}
\hline \multicolumn{1}{|c|}{ Bulan } & THN & $\begin{array}{c}\text { Jumla } \\
\text { hHari } \\
\text { Kerja } \\
\text { (Hari) }\end{array}$ & $\begin{array}{c}\text { Jam } \\
\text { Kerja } \\
\text { (Jam) }\end{array}$ & $\begin{array}{c}\text { Jam } \\
\text { istirah } \\
\text { at } \\
\text { (Jam) }\end{array}$ & $\begin{array}{c}\text { Jam } \\
\text { Operas } \\
\text { i (Jam) }\end{array}$ & $\begin{array}{c}\text { JidakP } \\
\text { rodukti } \\
\text { f(Jam) }\end{array}$ \\
\hline September & 2015 & 25 & 275 & 25 & 205,5 & 69,5 \\
\hline Oktober & 2015 & 26 & 260 & 26 & 181 & 79 \\
\hline November & 2015 & 25 & 275 & 25 & 204,5 & 70,5 \\
\hline Desember & 2015 & 25 & 275 & 25 & 199,5 & 75,5 \\
\hline Januari & 2016 & 24 & 264 & 24 & 202 & 62 \\
\hline Februari & 2016 & 24 & 264 & 24 & 212 & 52 \\
\hline Maret & 2016 & 25 & 275 & 25 & 209,5 & 65,5 \\
\hline April & 2016 & 26 & 260 & 26 & 201 & 59 \\
\hline Mei & 2016 & 24 & 264 & 24 & 197 & 67 \\
\hline Juni & 2016 & 26 & 260 & 26 & 188 & 72 \\
\hline
\end{tabular}

(Sumber : PT. Surya AgrolikaReksa, 2016)

\section{Availability Ratio}

Merupakan suatu ratio yang menggambarkan pemanfaatan waktu yang tersedia untuk kegiatan operasi mesin atau peralatan. Dengan demikian formula yang digunakan untuk mengukur availability ratio adalah:

$$
\begin{gathered}
\text { Availability Ratio }=\frac{\text { Operation Time }}{\text { Loading Time }} \times 100 \% \\
=\frac{\text { Loading Time-Downtime }}{\text { Loading Time }} \times 100 \%(1)
\end{gathered}
$$

a. Loading time

Merupakan waktu yang tersedia (available time) per hari atau perbulan yang dikurang dengan waktu downtime mesin yang direncanakan (plannned downtime).

b. Operation time

Merupakan hasil pengurangan antara loading time dengan downtime mesin (non-operation time) 
2. Performance Effeciency Ratio

merupakan suatu ratio yang menggambarkan kemampuan dari peralatan dalam menghasilkan barang. Terdapat tiga faktor yang dibutuhkan untuk menghitung Performance Effeciency Ratio yaitu:

a. Ideal cycle time

b. Processed amount

c. Operation time

Formula pengukuran rasio ini adalah:

Performance Effeciency Ratio

$=\frac{\text { Processed Amount } x \text { Ideal cycle time }}{\text { Operation Time }} \times 100 \%$

UntukmencariIdeal Cycle time:

$$
\% \text { Jam kerja }=1-\frac{\text { Total Delay }}{\text { Available Time }} \times 100 \%
$$

Dimana :

Waktu Siklus $=\frac{\text { Loading Time }}{\text { Hasil Produksi }} \times 100 \%$

Sehingga :

Ideal cycle time $=$ WaktuSiklus x \% Jam Kerja (6)

\section{Quality Ratio (Rate of Quality Product)}

Quality Ratio merupakan suatu ratio yang menggambarkan kemampuan peralatan dalam menghasilkan produk yang sesuai dengan standar. Formula yang digunakan untuk pengukuran ratio ini adalah :

Rate of Quality Product

$=\frac{\text { Processed Amount-Defect Amount }}{\text { Processed Amount }} \times 100 \%$

Pengukuran OEE ini didasarkan pada pengukuran tiga rasio utama, yaitu Availability Ratio, Performance Effeciency Ratio, dan Rate of Quality Product. Perhitungan nilai OEE pada bulan September 2015 dapat menggunakan rumus:

$\mathrm{OEE}=($ Availibility Ratio $\times$ Performance Efficiency $\times$ Rate of Quality Product)

Berikut adalah rekapitulasi hasil perhitungan nilai OEE (Overall Equipment Effectiveness) mesin Ripple Mill pada Bulan September 2015 - Juni 2016 pada Tabel 2.

Tabel 2 Rekapitulasi OEE Mesin Ripple Mill PT. SAR bulan September 2015 - Juni 2016

(Sumber: Pengolahan Data, 2016)

Berdasarkan Tabel2 diketahui bahwa nilai OEE terbesar terdapat pada bulan Februari 2016 dan terendah pada bulan Oktober 2015.Nilai OEE dipengaruhi berdasarkan hasil perkalian dari nilai ketiga factor ratio yaitu Availability ratio, Performance Efficiency Ratio, danRate of Quality

\begin{tabular}{|l|c|c|c|c|}
\hline \multicolumn{1}{|c|}{ Bulan } & $\begin{array}{c}\text { Availibility } \\
\text { Ratio (\%) }\end{array}$ & $\begin{array}{c}\text { Performance } \\
\text { Ratio (\%) }\end{array}$ & $\begin{array}{c}\text { Rate of } \\
\text { Quality } \\
\text { Product } \\
(\%)\end{array}$ & OEE (\%) \\
\hline September & 79,2 & 97,64405051 & 100 & 77,334088 \\
\hline Oktober & 77,3504274 & 94,49123204 & 100 & 73,08937179 \\
\hline November & 79,2 & 97,58156566 & 100 & 77,2846 \\
\hline Desember & 78,4 & 98,8 & 100 & 77,4592 \\
\hline Januari & 78,3333333 & 98,7823617 & 100 & 77,37951666 \\
\hline Februari & 78,75 & 103,8773545 & 100 & 81,80341667 \\
\hline Maret & 80,8 & 97,88423762 & 100 & 79,090464 \\
\hline April & 79,4871795 & 94,50595699 & 100 & 75,12011966 \\
\hline Mei & 78,75 & 98,14126984 & 100 & 77,28625 \\
\hline Juni & 77,7777778 & 96,38347253 & 100 & 74,96492308 \\
\hline Total & $\mathbf{7 8 8 , 0 4 8 7 1 8}$ & $\mathbf{9 7 8 , 0 9 1 5 0 1 4}$ & $\mathbf{1 0 0 0}$ & $\mathbf{7 7 0 , 2 7 1 8 0 5 2}$ \\
\hline Rata-rata & $\mathbf{7 8 , 8 0 4 8 7 1 8}$ & $\mathbf{9 7 , 8 0 9 1 5 0 1 4}$ & $\mathbf{1 0 0}$ & $\mathbf{7 7 , 0 2 7 1 8 0 5 2}$ \\
\hline PrOduct Berdasarkan & $\mathbf{h a s i l}$ & $\mathbf{p e r h i t u n g}$ \\
\hline
\end{tabular}

Product.Berdasarkan hasil perhitungan, pada Tabel2 diketahui bahwa nilai OEE tidak ada perbedaan yang signifikan untuk setiap bulannya.

Berikut adalah grafik persentase dari Overall Equipment Effectiveness mesin Ripple Mill PT. SAR bulan September 2015 - Juni 2016 yang dapat dilihat pada Gambar1.

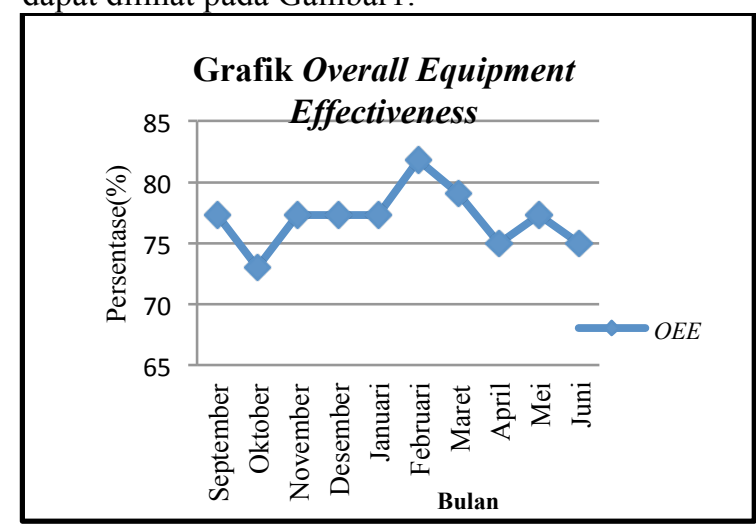

Gambar1 GrafikOEEMesinRipple Mill PT. SAR Bulan September 2015 - Juni 2016

Nilai OEE yang telah didapatkan dibandingkan dengan nilai OEE standar internasional yang merupakan nilai standar dari masing-masing faktor yang mempengaruhi nilai OEE, dengan begitu dapat diketahui apakah Availibility ratio, Performance Efficiency Ratio, dan Rate of Quality Product mesin Ripple Mill PT. SAR Bulan September 2015 - Juni 2016telah sesuai dengan nilai standar yang ada.

Berikut nilai perbandingan OEE perusahaan terhadap OEE standar Internasional pada Tabel 3 
Tabel

3PerbandinganNilai OEE Standar Internasional dengan Nilai OEE Mesin Ripple Mill PT. SAR Bulan September 2015 - Juni 2016

\begin{tabular}{|c|c|c|}
\hline OEE Factor & $\begin{array}{c}\text { Nilai OEE } \\
\text { StandarInternasional } \\
(\%)\end{array}$ & $\begin{array}{c}\text { Nilai OEE } \\
\text { MesinRipple } \\
\text { Mill } \\
\text { PT. SAR } \\
(\%)\end{array}$ \\
\hline $\begin{array}{c}\text { Availibility } \\
\text { Ratio }\end{array}$ & 90 & 78,8048718 \\
\hline $\begin{array}{c}\text { Performance } \\
\text { Efficiency } \\
\text { Ratio }\end{array}$ & 95 & 97,80915014 \\
\hline $\begin{array}{c}\text { Rate of } \\
\text { Quality } \\
\text { Product }\end{array}$ & 99 & 100 \\
\hline OEE & 85 & 77,02718052 \\
\hline
\end{tabular}

(Sumber: Pengolahan Data 2016)

Berdasarkan Tabel 3 dapat diketahui bahwa nilai perhitungan rata-rata dari Availibility Rati, dan OEE untuk mesin Ripple Mill belum mencapai standar Internasional, sedangkan nilai Performance Efficiency Ratio dan Rate of Quality Product dari Mesin Ripple Mill sudah mencapai standar Internasional yang ada.

Berikut dapat dilihat grafik pada mesin Ripple Mill PT. SAR Bulan September 2015 - Juni 2016 pada Gambar2.

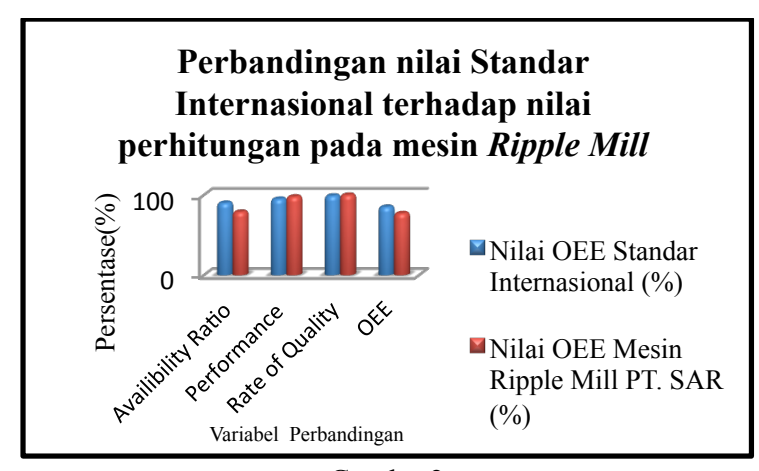

Gambar2

GrafikperbandinganantaranilaiStandarInternasionalterhad apnilaiperhitunganpadamesinRipple Mill PT. SAR Bulan September 2015 - Juni 2016

Nilai OEE ditentukan oleh factor seperti Availibility ratio, Performance Effeciency ratio dan Rate of Quality Product. Adapun penyebab tinggi rendahnya nilai-nilai tersebut ditentukan oleh beberapa factor permasalahan untuk dilakukan perbaikan, berikut diagram Fishbone untuk faktor yang mempengaruhi besaran nilai OEE pada mesin Ripple Mill padaGambar3.

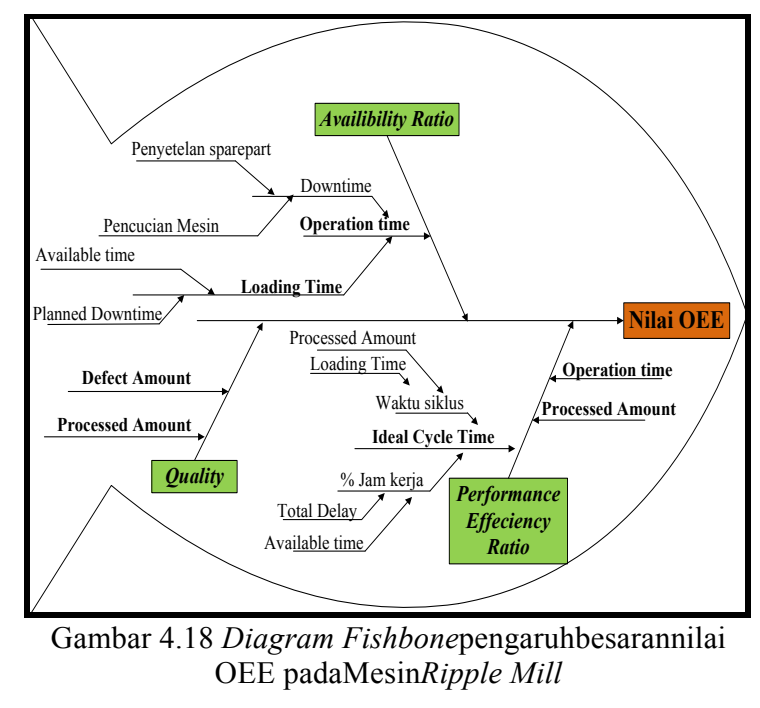

\section{Kesimpulandan Saran}

Berdasarkan hasil dari penelitian yang telah dilakukan, maka kesimpulan yang diperoleh adalah Nilai OEE pada bulan September 2015 -Juni 2016 yaitu sebesar 77,02718052\%. Persentase tersebut belum memenuhi standar Internasional sebesar $85 \%$ disebabkan tidak ada nilai OEE yang mencapai atau melebihi $85 \%$. Sehingga dapat disimpulkan bahwa berdasarkan nilai perhitungan OEE mesin Ripple Mill, secara umum variabel yang mempengaruhi besaran nilai OEE pada mesin Ripple Mill seperti Availibility Ratio, Performance Effeciency Ratio dan Rate of Quality Product memberikan hasil yang kurang baik. Hal ini disebabkan tingginya jumlah Downtime yang menyebabkan nilai Availibility Ratio, berada dibawah Standar Internasional.

Faktor-faktor dasar penyebab kerusakan atau permasalahan yang ada pada mesin Ripple Mill agar mesin dapat bekerja lebih optimal adalah Material disk samble dan rotor bar yang kurang keras menyebabkan komponen mudah aus ketika terjadi gesekan dengan biji kelapa sawit sehingga dilakukan perawatan berupa pengelasan apabila disk samble dan rotor bar tidak terlalu aus dan diganti apabila sudah terlalu aus. Hal ini menyebabkan mesin Ripple Mill bekerja dengan tidak optimal,akibatnya menghasilkan waktu downtime (non productive time).

Agar nilai Overall Equipment Effectiveness (OEE) mengalami peningkatan perusahaan disarankan untuk melakukan pemupukan secara menyeluruh pada perkebunan perusahaan, menjaga ketersediaan bahan baku dengan memperbanyak jumlah 
pemasok,memberikan pelatihan kepada petani tentang bagaimana cara merawat kelapa sawit yang benar dan melakukan penyiraman kelapa sawit secara rutin untuk memenuhi kebutuhanm air yang diserap kelapa sawit. Menggunakan rotor bar dengan tingkat kekerasan material yang lebih tinggidan menggunakan disk samble dengan tingkat kekerasan material yang lebih tinggi serta pembersihan mesin dilakukan lebih awal sebelum mesin beroperasi.

\section{DaftarPustaka}

[1] Corder, Anthony.1973. Teknik Manajemen Pemeliharaan. Erlangga, Jakarta.

[2] FahmiAfif, RahmanArif, danEfranto,Y.R, 2015, Implementasi TPM padaMesin Rotary KTH-8, Jurnal, UniversitasBrawijaya, Malang.

[3] Ginting, S, M. 2007. Usulan Perbaikan Terhadap Manajemen Perawatan Dengan Menggunakan Metode Total Productive Maintenance (TPM) Di PT. Alumunium Extrusion Indonesia (Alexindo). Tugas Akhir Fakultas Teknologi Industri Universitas Guna Darma.

[4] Hasriyono, M., 2009, Evaluasi Efektivitas Mesin dengan TPM, Repository, Universitas Sumatera Utara, Medan.

[5] Jiwantoro, A., Argo, D.B., danNugroho, A.W, 2013, Analisa Efektivitas Mesin Penggiling Tebu Dengan TPM, Jurnal, Universitas Brawijaya, Malang.

[6] Jono, 2006, Total Productive Maintenance pada perawatan mesin Boiler, Jurnal Ilmiah Teknik Industri dan Informasi Jurusan Teknik Industri, Universitas Widya Mataram, Yogyakarta.

[7] Mahdina, N.A, Sugiono, danYuniarti,R., 2015, Peningkatan Efektivitas Produksi Pada Sistem Produksi Kontinyu Dengan TPM, Jurnal, Universitas Brawijaya, Malang.

[8] Mckellen, Chris. 2005. Overall Equipment Effectiveness. Production Management.

[9] Nakajima, S. 1988, Introduction to Total Productive Maintenance. Productivity Press, Cambridge, MA.
[10] Purnomo, H., 2004, PengantarTeknikIndustri, Grahallmu, Yogyakarta.

[11] Rinawati, I.D., 2014, Analisis Penerapan Total Produktive Maintenance (TPM) menggunakan Overall Equipment Effectiveness (OEE) dan Six Big Losses, Jurnal, Universitas Diponegoro, Surabaya.

[12] Roberts,J.1997.Total Productive Maintenance. The Technology Interface, New Mexico State University, www.et.nmsu.edu, Las CrucesNew Mexico

[13] Suhendar,E., 2010, Analisis Overall Equipment Effectiveness pada mesin Plat Roll Ironer, Jurnal Ilmiah Faktor Exacta, Universitas Indraprasta PGRI.

[14] Sukwadi, R. 2007. Analisis Perbedaan Antara Faktor - Faktor Kinerja Perusahaan Sebelum Dan Sesudah Menerapkan Strategi Total Productive Maintenance (TPM) (Studi Kasus pada PT. Hartono Istana Teknologi Divisi Produk Home Appliances). Tesis Program Studi Magister Manajemen Universitas Diponegoro. 